https://doi.org/10.48009/1_iis_2007_97-102

\title{
ADDRESSING THE DECLINE IN CIS ENROLLMENT
}

\author{
Lissa Pollacia, Northwestern State University, pollacia@nsula.edu \\ Jack Russell, Northwestern State University, jrussell@nsula.edu
}

\begin{abstract}
It is widely known that since the year 2000, the number of U.S. students who choose Computer Information Systems (CIS), Management Information Systems (MIS), or Computer Science (CS) as a major has declined significantly. For many CIS departments, a portion of their budget is tied to the number of student credit hours that are produced. There are ways to increase these numbers, such as offering more service courses to the general student body. A department may also consider offering multi-disciplinary minors that incorporate computerintensive courses taught by other departments. This paper presents a review of CIS minors offered at institutions in the U.S. The results of the review shows information such as the type of minor, the number of credit hours, and the types of courses that are typically required. It is our hope that this study will provide information to assist anyone considering curriculum changes.
\end{abstract}

Keywords: CIS Program, Computer majors, Enrollment, Information Technology Curricula

\section{INTRODUCTION}

All statistical evidence points to a steady decline in the number of students who are electing to major in science, technology, engineering, and mathematics (STEM). Particularly hard hit are all computingrelated fields, such as Computer Information Systems (CIS), Computer Science (CS), and Management Information Systems (MIS) [14]. The decrease in computing enrollments coupled with a large number of pending baby-boomer retirements is expected to create a substantial shortage of skilled workers in the U.S. in the coming years [2, 5, 9].

Recent studies show that there are a variety of reasons for this decline, such as students' inaccurate perception of the computing profession, particularly with respect to job prospects and career opportunities. Other reasons cited are the dot com bust, the outsourcing of jobs overseas, the decline in students' analytical abilities, and the perception of "geek"/"nerd" for computer professionals. A large number of students indicated that they think the work will be too hard or technical $[7,13]$.
Now the question is: what can we do about this situation? In answer to declining enrollments and increasing employer demands, many computing programs are examining ways to provide course offerings to a wider audience of students. One way to do this is by increasing the number of service courses that are used to fulfill basic electives or core requirements. Another option is the introduction of CIS minors for non-majors. A third option is to develop interdisciplinary minors in partnership with other departments throughout the university.

The authors have conducted a review of minors offered in CIS at colleges and universities in the United States. We found that a CIS minor may also be known by other names, such as Information Systems (IS), Information Technology (IT), Computing Sciences and so forth. However, the overwhelming majority are called CIS, therefore in this paper we will use CIS to refer to this list of titles collectively.

We collected data concerning the type of minor (traditional vs. multi-disciplinary), the number of credit hours and the types of courses that are generally included. We then analyzed this data to determine commonalities and differences in these minors. Some of the innovative multi-disciplinary minors are described. It is the author's hope that this study will provide information to faculty who may be considering curriculum changes, particularly with respect to minor degree programs.

\section{REASONS FOR THE DECLINE}

In a recent survey of faculty at U.S. universities that offer a bachelors degree in Computer Information Systems, Management Information Systems, or Information Technology [6], seventy-six (76.1\%) of the respondents reported that enrollment had decreased in the past two years. When questioned about the reasons as to why they felt that enrollment had declined at their institutions, sixty-seven (67\%) blamed the outsourcing of jobs, sixty (60\%) stated the economy in general, sixty $(60 \%)$ cited the dot com failure, forty (40\%) indicated that the drop was cyclical in nature, and twenty-seven (27\%) stated it was due to decline in students' analytical abilities.

The author's own recent research has provided some information concerning the cause for the enrollment 
decline [7, 13]. In a survey of students in introductory computer literacy courses, many of the students reported that they did not choose a computer-related career due to inaccurate or insufficient information concerning computing careers. The results also show that students have a high level of dissatisfaction with their high school counseling experience, and received little or no guidance, particularly with respect to the computing profession.

Other reasons cited were the lack of interest in a computer-related profession; they did not think they would like the work; they thought the work would be too hard; or they did not think that there were very many jobs available in this field.

A related study produced very similar results. Respondents in this study were business students in introductory business classes. The respondents indicated that they were knowledgeable about careers in management, marketing, accounting, and finance; and were least knowledgeable about information systems. To sum it up: "This generation, which is noted for its pervasive use of technology, has little interest in, or awareness of, the occupations that drive the digital age" [3].

\section{PERCEPTIONS VS. REALITY}

In actuality, students' perceptions of career opportunities are not aligned with reality. The majority of students have poor information and misconceptions about nearly every aspect of the profession.

According to the U.S. Department of Labor, highlevel jobs that combine technical and business skills are still abundant in the U.S. The Bureau of Labor Statistics projects that the number of jobs in the industry sector Computer Systems Design And Related Services, will increase by 54.6\% from 2002 to 2012 [1]. In fact, the bureau predicts that eight of the eleven fastest-growing occupations through 2012 that require a bachelor's degree will be in this sector.

Other employment analysts write that the recent upturn in the U.S. economy has resulted in continued growth, and is particularly good for information systems. The hiring in information systems is slated for continued growth [4, 12]. MONEY Magazine and Salary.com, a leading provider of employee compensation data and software, researched hundreds of jobs and compiled a list of the "Top 10 Best Jobs in America” [8]. The careers shown in Table 1 were rated the highest.

\begin{tabular}{|l|}
\hline 1. Software Engineer \\
\hline 2. College professor \\
\hline
\end{tabular}

\begin{tabular}{|l|}
\hline 3. Financial adviser \\
\hline 4. Human Resources Manager \\
\hline 5. Physician assistant \\
\hline 6. Market research analyst \\
\hline 7. Computer IT analyst \\
\hline 8. Real Estate Appraiser \\
\hline 9. Pharmacist \\
\hline 10. Psychologist \\
\hline
\end{tabular}

Table 1: Top 10 Best Jobs in America

The criteria for rating the jobs included projected job growth, annual salary, work environment, annual job openings, stress levels, flexibility in hours, creativity, and the opportunities for advancement in the field.

The reality is that the area of information systems is one of the fastest growing areas of employment, with high salaries and earning potential. Two of the 10 most highly rated jobs are in this area. Therefore we need to educate potential students to see information systems as an energetic and growing profession, with outstanding long-term job security, salary prospects, and prestige.

\section{RECRUITING IN PLACE}

What can we do to recruit more students? One of the low-cost measures that a CIS department may undertake is to engage in "recruiting in place". This is a term that we use to describe activities to increase enrollments by recruiting students who are already enrolled in our own institutions. These students are majoring in other disciplines: art, history, math, science, journalism. This is not an attempt to sway these students to change majors; but rather to provide more opportunities to increase their computing skills within their chosen major.

This requires a shift in our thinking, as we are generally focused only on our majors. We need to become more aware of the inter-disciplinary nature of CIS, and learn to collaborate with other disciplines on our campuses. A few institutions have embraced this idea of recruiting in place, and found that the most direct path to enticing students to take more CIS courses is by offering a minor that enhances their own chosen field of study.

For example, at our institution, Northwestern State University, we have recently instituted a composite minor in web development that consists of six courses (18 hours). Four of the courses are from CIS; the other two are graphics art/design courses. The sequence of courses is fixed; however one-third of the curriculum is from the Art Department [14].

The motivation for delivering this curriculum is to provide skills that Web developers/designers 
generally need. While Web designers need to possess general design skills, such as an understanding of drawing and a how to create aesthetically pleasing combinations of color and form, they also need an understanding of Webspecific design factors, such as screen resolution, image compression, usability, accessibility, and website architecture. Rudimentary knowledge of programming and database systems is also important on the technical side.

We wanted to enhance the technology skills of Art majors through web development courses, and to enhance the artistic skills of CIS majors through visual and graphic design. In addition to Art and CIS majors, students of any major may also enroll in this minor. The result will be students who can both design and implement web sites more effectively.

\section{CIS MINOR}

As previously stated, a CIS minor may be known by other names, such as Information Systems or Information Technology. The number of credit hours and curriculum of a CIS minor is different for virtually every institution. The majority of the CIS minors are what we call traditional. The traditional CIS minor is essentially a scaled-down version of the CIS major, with all of the required classes coming from the CIS department.

We also define two other categories of CIS minors: composite and multi-disciplinary. The composite minor is one where a majority of the courses are from the CIS department; however the student also takes courses from one other major area to complete the degree. The CIS/Art minor in web development described in the previous section is an example of a composite minor.

We use the term multi-disciplinary to designate minors that focus on the study of information technology through its application in many fields. Departments offering computer-centric courses may include art, computer science, English, journalism, biology, and so forth. There is generally a required number of courses that must be taken from the computing department before the student takes elective courses from the other departments.

An example of a multi-disciplinary minor is the IT minor at the University of North Carolina Wilmington [10]. The minor requires 3 computer science courses, i.e. Fluency of Information Technology, an introductory programming course, and one other computer science course of the student's choosing. There is an additional required course offered by the university library. This course was created specifically for the minor, and teaches the student how to conduct research using computer technology. The remaining two courses are chosen from those offered by other departments that heavily involve computer technology as a component of the course. These other areas include: Art, Chemistry, Communications, Educational Technology, English, Film Studies, GIS, Music, Logic, and Sociology.

\section{METHODOLOGY}

We gathered data about CIS minors that are offered in U.S. colleges and universities. The data was gathered via Internet search and through a search of the following directories and databases:

\section{Directories:}

College Blue Book

American Universities and Colleges

Patterson's American Education

\section{Databases: \\ ERIC \\ Professional Development Collection in Education \\ Business Source Premier \\ Computer Science Index \\ Computer Source \\ Information Science and Technology Abstracts}

This search revealed that there is no compiled listing of minors in CIS.

The keywords used for the Internet search were: "minors", "Computer Information Systems" and "Information Technology”. We found fifty-five sites that provided complete and relevant information.

We reviewed the results of the search, and listed the following information about each minor: the name of the institution, the name of the minor, category (Traditional, Composite, or Multi-disciplinary), the number of credit hours, the number of elective credit hours, and any special requirements.

In addition, we examined the courses that constitute the curriculum to determine if there were any commonalities. As we reviewed the minors, we began to discover that certain courses were commonly included, either as required or elective. This is the list of courses that were the most frequently included as part of the minor:

(1) Introduction to Information Technology

(2) Programming I (Introduction to Prog.)

(3) Management Information Systems

(4) Database Systems

(5) Systems Analysis and Design

(6) Web Development/Design 
(7) Telecommunications/networks

\section{RESULTS OF THE STUDY}

The authors were interested in determining if there are particular commonalities among minors by the title (CIS, Information Technology, Information Systems etc.) or by Category (Traditional, Composite or Multi-disciplinary). The commonalities could include information about which type of courses are being taught in the minor, the number of total credit hours and the total number of electives in the minor. In performing this research, the sample included 55 CIS minors offered by universities and colleges. The survey variables were stored into an Excel spreadsheet where pivot tables were created to cross tabulate the results.

Among the 55 minors in the data set, the most frequently occurring titles were CIS (58\%), Information Technology (24\%) and Information Systems (5\%). The "Other" category included those who had a title that appeared just once in the data set.

\section{Research Questions:}

The authors developed a series of research questions that focus on discovering if there were significant differences in the types of courses and number of credit hours among either the Minor Title or the Category (Traditional, Composite, and Multidisciplinary). The following research questions are:

1. How similar or different are the average number of credit hours and the number of elective hours among the Minor Titles (CIS, IS or IT)?

2. How similar or different are the average number of credit hours and the number of elective hours among the Categories (Traditional, Composite or Multi-disciplinary)?

3. Of the total count of schools surveyed what percentage of the schools were Traditional, Composite or Multi-disciplinary?

4. What percentage of the surveyed minors include one or more of the common courses listed in the previous section?

\section{Research Question 1:}

Table 2 illustrates the results in determining the similarity and difference in credit and elective hours among the Minor Titles (CIS, IS, or IT).

\begin{tabular}{|l|l|l|l|l|}
\hline Minor Title & Avg \# Credits & $\begin{array}{l}\text { Avg \# } \\
\text { Electives }\end{array}$ & Count & Percentage \\
\hline & & & & of Total \\
\hline CIS & 19.1 & 5.6 & 32 & $58 \%$ \\
\hline $\begin{array}{l}\text { Information } \\
\text { Technology }\end{array}$ & 18.5 & 10.5 & 13 & $24 \%$ \\
\hline $\begin{array}{l}\text { Information } \\
\text { Systems }\end{array}$ & 22.0 & 6.6 & 3 & $5 \%$ \\
\hline Other & 17.9 & 9.3 & 7 & $13 \%$ \\
\hline TOTAL: & $\mathbf{1 9 . 9}$ & $\mathbf{7 . 6}$ & $\mathbf{5 5}$ & \\
\hline
\end{tabular}

Table 2: Minors Based on Average Credits and Elective Hours

The average number of credit hours to complete the minor is 19.1 for CIS, 22.0 for Information Systems and 18.5, respectively. The number of credits required to complete the minor ranged from 15 to 30 .

The difference in average credits is insignificant, but the difference in elective hours is significant between the IS minor and the other two. Graph 1 below illustrates this difference graphically. The authors find this interesting and as part of future work, hope to find more minors with the title Information Systems, and rerun the statistical analysis.

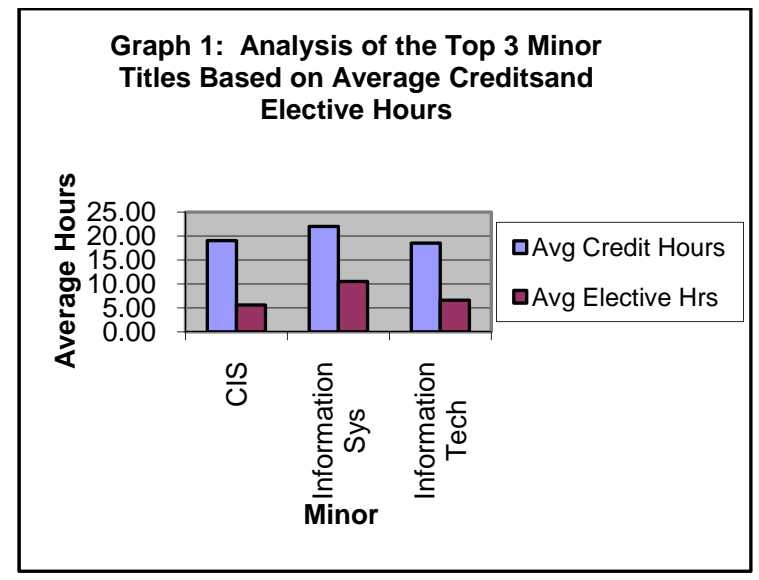

Research Question 2:

Graph 2 below illustrates a comparison of the average credit hours with elective credit hours by Category. The authors first predicted that the Multidisciplinary sub-category would have a higher percentage of elective hours in the minor. However, the Composite minor carried a disproportionately larger percentage of elective hours than the other two. This is possibly due to the fact that this minor involves CIS working in cooperation with one other department, which possibly wants to include as many of its courses in the minor as possible. 


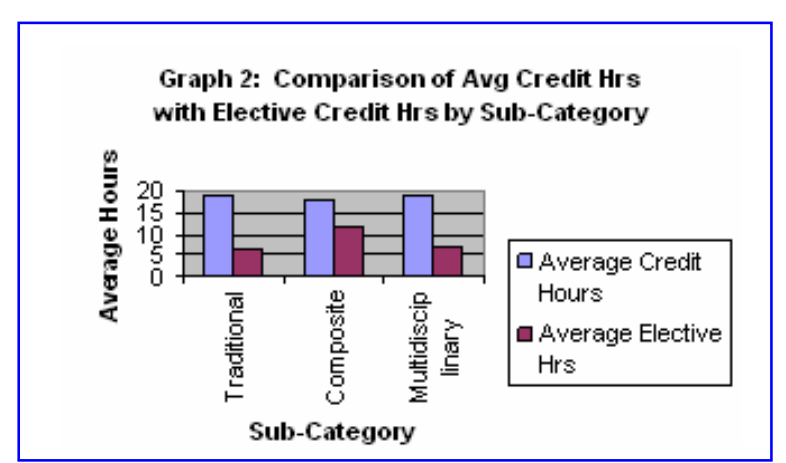

With a small percentage of the total count contributed by Composite and Multi-disciplinary the authors fear that chance factors alone may have caused this unexpected result. In future studies, we hope to find a larger number of Composite and Multi-disciplinary minors and rerun the statistical analysis.

\section{Research Question 3:}

Table 3 shows the percentages of schools surveyed that were Traditional, Composite or Multidisciplinary. A cursory glance indicates that 87 percent fall in the Traditional category, 4 percent are Composite, and 9 percent are classified as Multidisciplinary.

\begin{tabular}{|l|l|l|}
\hline Category & Count & Percentage \\
\hline Traditional & 48 & $87 \%$ \\
\hline Composite & 2 & $4 \%$ \\
\hline Multi-disciplinary & 5 & $9 \%$ \\
\hline
\end{tabular}

\section{Table 3: Comparison of Minor Categories by Count and Percentage}

The large disproportion between the Traditional category and the other two categories indicates that of the institutions reviewed, very few have developed a composite or multi-disciplinary minor.

\section{Research Question 4:}

For this question, we wanted to determine what percentage of the minors included one or more of the common courses listed in the previous section.

The results of our analysis are shown in Table 4. Of the minors reviewed, the overwhelming majority (76\%) required a Programming I course. The courses had a variety of course titles, but in general could be considered an introduction to programming. A database course was included by $60 \%$ of the minors, and some sort of Introduction to Information Technology course was included by $56 \%$ of the minors that we reviewed.

Table 4. Courses are included in all minors (required or elective)
One unexpected finding was that such a high percentage of minors that do not require a traditional

\begin{tabular}{|l|l|l|}
\hline Course & $\begin{array}{l}\text { Count } \\
\text { minors }\end{array}$ & $\begin{array}{l}\text { Percentage } \\
\text { of Total }\end{array}$ \\
\hline Programming I & 42 & $76 \%$ \\
\hline Database Systems & 33 & $60 \%$ \\
\hline Introduction to IT & 31 & $56 \%$ \\
\hline Systems Analysis and Design & 24 & $44 \%$ \\
\hline Web Development/Design & 23 & $42 \%$ \\
\hline Management Inf. Systems & 21 & $38 \%$ \\
\hline Telecommunications/Network & 20 & $36 \%$ \\
\hline
\end{tabular}

Introduction to IT course. It remains unclear if the lack of an introductory course might an impact on the success or failure of a student who chooses one of these minors.

\section{CONCLUSIONS}

For several years now, U.S. colleges and universities have seen a steady decline in students majoring in STEM disciplines, particularly in computer-related fields. While there are a variety of reasons for this decline, much of the problem stems from misinformation or lack of information concerning the discipline, career opportunities, nature of the work, and concern of the outsourcing of jobs overseas.

One of the ways to address this decline in enrollments is "recruiting in place", which we define to be recruitment of students who are already on campus. Developing curricula for a minor targeting non-majors is one way to enroll more students into their courses.

We collected data to determine what types of CIS minors are currently being offered by U.S. institutions. We found that, for the institutions that we examined, the overwhelming majority of CIS minors are traditional, meaning that all courses in the curriculum are CIS courses. A small percentage of those reviewed were composite minors, which means the CIS department partners with one other department. A small number of minors were classified as multi-disciplinary, where the courses that comprise the minor may come from a cross section of disciplines.

In examining the course offerings within the minors, we found that there are some commonalities concerning the courses included in the curriculum. The most commonly included classes were Introduction to Programming, Database Systems, and Introduction to Information Technology. The number of course credits required to complete the minor ranged from 15 to 30, with the average being approximately 19 credits, with 8 credits of electives. 
This study is the first step taken by our CIS department to recruit more students on our own campus. We wanted to determine what other institutions were doing with respect to offering minors. We had hoped to find more multidisciplinary minors that we could use as a model for developing one for our own campus.

Future work will include a more thorough examination of those institutions that offer a bachelor's degree in CIS, IS, and IT, using the College Blue Book, which has a compiled listing of schools by degrees. We feel that by increasing our data pool, we will obtain more reliable statistical results. In addition, we hope gain additional insight by discovering more innovative multi-disciplinary and composite CIS minors.

\section{REFERENCES}

1. Bureau (2006) Occupational Outlook Handbook, 2006-07 Edition, Bureau of Labor Statistics, U.S. Department of Labor, retrieved from the Bureau of Labor Statistics web site on 1/4/2007: http://www.bls.gov/oco/oco2003.htm.

2. Chabrow, E., (2004, Aug 16) "By the Book: Declining computer-science enrollments should worry anyone interested in the future of the U.S. IT industry”. InformationWeek, August, 2004, retrieved from Information Week website on 5/5/2007:

http://www.informationweek.com/shared/printab leArticleSrc.jhtml?articleID=29100069.

3. Crampton, William J., Walstrom, Kent A., and Schambach, Thomas P. (2006, October) "Factors Influencing Major Selection by College of Business Students”, Issues in Information Systems, October 2006, International Association for Compute Information Systems, Vol. VII(1), 2006, p. 226-230.

4. Fisher, Annie. "Hottest College Degrees for Getting Hired”. Fortune, Sept. 8, 2006. retrieved from CNNMoney.com website on 1/4/2007:

http://money.cnn.com/2006/09/07/news/econom y/hottest.majors.fortune/index.htm.

5. Kessler, Michelle (2005, May 23) Fewer Students Major in Computer: Some Fear Shortage of U.S. Workers, More Outsourcing. USAToday, retrieved from USAToday web site on 7/12/2005: www.usatoday.com/printedition/money/2005052 3/1b_computerscience23.art.htm.

6. Lenox, Terri L., Charles R. Woratschek, and Gary A. Davis (2005, October) "Exploring Declining CS/IS/IT Enrollments”, Proceedings of ISECON 2005, v22, Columbus, OH, Oct. 2005.

7. Lomerson, William and Pollacia, Lissa. (2005, October) "Declining CIS Enrollment: An Examination of Pre-College Factors". Proceedings of ISECON 2005, v22, Columbus, OH, Oct. 2005.

8. Money (2006, January) Top 10 Best Jobs in America. Retrieved from CNNMoney.com website on 1/3/2007: http://money.cnn.com/magazines/moneymag/bes tjobs/.

9. Murphy, Chris (2005, October) "Speak Up for the IT Career”. InformationWeek, Oct. 3, 2005, retrieved from Information Week website on 12/5/2005: www.informationweek.com/shared/ printableArticleSrc.jhtml?articleID=171202135.

10. Patterson, David A. (2005, September) "Restoring the popularity of Computer Science", Communications of the ACM, Vol 48, Issue 9, Sept. 2005, pages 25-28.

11. Patterson, Laurie J. (2005, June) "Reaching a New Audience: Development of ComputerCentric Minor”, Proc. 2005 ASCUE Conference, Myrtle Beach, South Carolina, www.ascue.org.

12. Paulson, Linda Dailey. (2006, September) "IT Hiring Growth Modest, But Steady," IT Professional, vol. 08, no. 1, pp. 6-9, Jan/Feb, 2006.

13. Pollacia, Lissa and Lomerson, William. (2006, October) “Analysis of factors affecting declining CIS enrollment”, Issues in Information Systems, October 2006, International Association for Computer Information Systems Vol. VII(1), 2006, p. 220-225.

14. Pollacia, Lissa and Lomerson, William. (2004, October) "Preparing Students with Integrated Skills in E-Commerce and Visual Design," Issues in Information Systems, International Association for Computer Information Systems, Vol. V(2), 2004, p. 654.

15. Vegso, Jay (2005, May) "Interest in CS as a Major Drops Among Incoming Freshmen”. Computing Research News, Vol 17/No. 3, May 2005. 